\title{
The Role of Plato and Aristotle in the Formation of Orthodoxy and Catholicism
}

\section{Kortunov Vadim Vadimovich}

Doctor of Philosophical Sciences, Professor, Head of the Department of Philosophy, Sociology and Psychology, Russian State University of Tourism and Service, 141221, Moscow region, Pushkinskiy District, Urban-Type Settlement Cherkizovo

Glavnaya street 99, Russian Federation

\section{Lapshin Ivan Yevgenyevich}

Candidate of Philosophical Sciences, Teaching Assistant of the Department of Ethics, Faculty of Humanities and Social Sciences, Peoples' Friendship University of Russia, 117198, Moscow, Miklukho-Maklay street 10a, Russian Federation

\section{Krasnova Olga Nikolaevna}

Candidate of Political Sciences, Associate Professor of the Department of Philosophy, Sociology and Psychology, Russian State University of Tourism and Service, 141221, Moscow region, Pushkinskiy district, urban-type settlement Cherkizovo Glavnaya street 99, Moscow, Russian Federation

\section{Kireenkova Zoya Alexandrovna}

Senior Lecturer of the Department of Philosophy, Sociology and Psychology, Russian State University of Tourism and Service 141221, Moscow region, Pushkinskiy district, urban-type settlement Cherkizovo, Glavnaya street 99, Russian Federation

\section{Prokhorov Mikhail Fyodorovich}

Doctor of Historical Sciences, Professor of the Department of Philosophy, Sociology and Psychology, Russian State University of Tourism and Service, 141221, Moscow region, Pushkinskiy district, urban-type settlement Cherkizovo Glavnaya street 99, Russian Federation

\section{Doi:10.5901/mjss.2015.v6n5s1p428}

\section{Abstract}

The article compares views of Plato and Aristotle regarding their attitude to the problem of rationality. As a matter of fact, Plato and Aristotle take totally opposite stands on the question of the essence of philosophy, its subject and methods; they appeal to mutually incompatible interpretations of the very bases of being. For Plato, true being is spiritual, transcendent; it doesn't fit in any rational-logical boundaries. For Aristotle, true being is corporeal and sensual; it is quite cognizable through rational-logical thinking. For Plato, the corporeal-sensual is an illusory "shade" of spirit; for Aristotle the very absolute spirit is a theoretical assumption, and this compulsory assumption, as a methodological admission, is necessary to substantiate the reality of the corporeal-sensual, "bodily" world. Aristotle most clearly formulated the idea of rational-logical totality which was very popular in ancient metaphysics and with which naturalistic philosophers, the Eleatics and the Sophists were mostly concordant. Whereas Plato "discovered" the transcensus and outlined the ways to the overrational and rather to the irrational-mystical comprehension of philosophical problems. In this sense, he constituted the opposition to the rational-logical tradition of ancient Greece as well as Orphics and Pythagoreans. Plato argued that the truth is the spiritual reality itself which is initially exposed to people: it is beyond contradictions and it embodies true being. He concludes from this that forms of being and forms of logical thinking are different. For Aristotle, on the contrary, the truth is the correspondence between forms of thinking and forms of being; it's not the reality, but the reflection of the reality in structures of human consciousness. It is notable that this very treatment of the truth gained a foothold in West European philosophy and science. These two tendencies, aimed at the development of the rational and irrational models of the world, were elaborated further in the Christian tradition, continually "arising" in the form of discussions of the relation between faith and knowledge, of different ways of knowledge of God.

Keywords: rationality, logic, the emotional, the irrational, Christianity.

\section{Introduction}

Ancient philosophy offers a very extensive and diverse material for study. Here we can find the most different views on people, society and culture. However, considering the declared theme, the $4^{\text {th }}-3^{\text {rd }}$ centuries B.C. are of the most interest 
for us because it was, in some sense, a critical period in the history of ancient culture. It was the time of decline of polis consciousness, separation of science and philosophy from mythological concepts, and development of actually scientificphilosophical toolkit. In this period ancient philosophy achieved an unprecedented level of abstracting, which allowed it to exceed the limits of study of physical-empirical being and turn to the sphere of the spiritual and transcendent. In this context the problem of correspondence between spiritual and physical culture, between aesthetics of spirit and flesh also becomes more distinct.

\section{Early Premises of the Divergence between Plato and Aristotle}

From this point of view, the figure of Socrates (469-399) is of great interest for us. It is no coincidence that a number of great modern philosophers link his name with "the great turn in philosophy" (M. Heidegger), consider him to be "the beginning of European culture" (H. Hegel), call him "a symbol of philosophy" (K. Marx). Indeed, his teaching largely determined the range of problems of all subsequent metaphysical science in the sphere of ethics, aesthetics and anthropology, but also, which is more crucial for us, it set the methodological basis of scientific search. Socrates spread skepticism among Athenians, calling for strictly logical, scientifically substantiated thinking. He indicated rational conclusiveness as the basis for the existence of the true knowledge. Following Parmenides, Zeno and the Sophists, Socrates became a spokesman of the idea that the universe can't be comprehended by senses only which are deceptive and subjective. Socrates and then Plato and Aristotle tried to substantiate the intellectualistic way of development of scientific-philosophical knowledge which later became general and predominant in the history of the ancient as well as all Western European culture.

Socrates proceeded from the objective-idealistic conviction according to which the world is founded on some rational basis which provides universal order. Is it conceivable to suppose that the world around has such obvious regularities and orderliness only due to a coincidence? Is it conceivable to assume that the natural harmony around us is a consequence of some blind, unreasonable force? To assume this, according to Socrates, means to admit that the world around "preserves such order due to some madness" (1, P.4). But if the world is based on the overall rationality, then rational human activity can serve as the most appropriate way of knowledge. Thus originated the rational philosophical tradition which oriented itself on discursive thinking and strictly logical argumentation.

This tradition proved to be so considerable for all European culture that further, in the Middle Ages, when Christianity offered Europe a new world view and a new system of values, the problem of relation between faith and knowledge, religious mysticism and scientific conclusiveness became the main subject of philosophical and theological disputes. Even medieval theism couldn't fully overcome the contradictions that arose between Christian world view and Western striving for scientific rationalization. The mere fact that medieval type of mentality was eventually overcome (although this "overcoming" lasted several centuries) and that Western European culture returned through the Renaissance to the necessity of constructing a more appropriate scientific world view testifies to the enduring archetypal prevalence of the rational over the irrational, the conceptual over the imaginative, the discursive over the poetic in Western mentality.

If we turn to the early Middle Ages, we find there absolute mental dominancy of Greco-Roman traditions against which Christian culture rose (so, it is natural that Latin became the language of Christianity and Rome - the capital and the center of cultural life). The problem of relationship between faith and knowledge, between Christian dogmas and metaphysical verities became one of the typical problems of philosophy (especially for patristics). Origen, developing the theory about three meanings of the Bible (literal, moral and philosophical-metaphysical), preferred the latter unconditionally. It is absolutely natural that the development of Christian world view in Europe has stopped in the time of scholastic teachings (Anselm of Canterbury, Pierre Abelard, Thomas Aquinas, Albert the Great, John Duns Scotus, William of Ockham) which were the attempts of rational-logical interpretation of Christianity. For example, Thomas Aquinas tried to systematize Christian knowledge rationally and to derive logical proofs of the existence of God appealing to common sense. Of course, the impact that scholastics had on the further development of Christian doctrine and world view altogether is uncertain. On the one hand, the strict categorical-logical apparatus helped to preserve the continuity of intellectual skills and scientific methods which later appeared to be demanded by the culture of modern era. On the other hand, in our opinion, the ultimate rationalization and logization of Christianity didn't contribute to its true, spiritual understanding. So, the whole experience of religious development of Europe shows how theology, trying to correlate with rationalistic world view, is always looking for "some compromise, some centerline between divine mystery and human logic" (2, P. 82). Rationalistic interpretation of Christianity apparently wasn't inevitable, though. Philosophical reading of Christian dogmas became more "delicate" and artistic-imaginative in Byzantine tradition, which was clearly witnessed by all Eastern patristics (Basil the Great, Gregory of Nyssa, Gregory the Theologian, Amphilochius of Iconium etc.) 
This problem which later provoked the contradictory "confluence of Greco-Roman thought with theistic and personalistic Christianity" (3, P. 117) arose in antiquity in the form of metaphysical "dispute" between emotionalmythological world view and the scientific-rational spirit of Greek philosophy which brought up anthropological questions. Socrates was one of the first who brought this "dispute" to the critical point without fear of sacrificing traditional ideals of polis Greece. To some extent, the ideas of Socrates can be considered as a natural continuation of the philosophy of the Sophists which asserted the priority of personality and individuality over the authority of social ethics of the polis. As early as in the philosophy of the Sophists the "reorientation" of ancient mentality towards the anthropology and subjective ethics can be traced clearly; Protagoras (490-420) already, stating that "as every man perceives everything so it is for him most likely" (4, P. 152), tried to query the primacy of the substantial over the individual, to oppose creative-axiological abilities of subject to traditional stereotypes of polis culture.

The emergence of sophism as philosophical teaching was naturally connected with the development of socialpolitical situation of Greece of that time. The $4^{\text {th }}$ and $3^{\text {rd }}$ centuries were centuries of the rise of ancient democracy. Solon's reform delivered a crushing blow to nobility, proclaiming a direct relationship between political freedom and pecuniary and economic capabilities of polis citizen. Of course, such rapid changes in social life also provoked the need of revision of basic ideological principles. Philosophers of that time started a thorough development of several problems connected with political reorganization of the state and changes in social relationships. Thus emerged the problem of status of the individual which Socrates discussed thoroughly and productively; the problem of correlation between freedom of will and enforcement the analysis of which we find in works of Solon and Aristotle; the problem of correlation between natural, civil and social law which was developed in works of Democritus and the Sophists. Finally, ancient thinkers began discoursing on possible types of government.

It was quite natural that in this situation the question about correlation between common and private, universal and individual, state and personal interests became immensely relevant. Starting with the Sophists and Socrates (who practically put an end to polis mentality and proved the inherent value of the human individual), the problem of the individual and the universal became central in Western European political science and philosophy. Citizens of polis Greece realized not only that they are a self-sufficient value but also that the political life of the state depends on them. Intellectual agitation of this period gave birth to many ideas including those of a proto-liberal kind.

The development of Athenian democracy stimulated the revision of the nature of social laws itself, prompting Greeks to realize their social (and not divine) origin. In this way arises skepticism towards mythological traditions which consider laws of social-political life as an invariable and firmly established manifestation of supernatural will. From this time ancient people began to realize their role in forming social-political life as well as common axiological principles more and more distinctly. Mythological authorities and appeals to divine providence gradually yielded to arguments of human mind, and systems of logical reasoning became methods of proof. All this contributed to the development of pluralism and the formation of principles of thinking variability (5, P. 27).

The social-political circumstances also demanded new philosophical views. The focal point of ancient metaphysics gradually shifted from the problems of natural philosophy to anthropological, social-political, ethical and aesthetic problems. Relativism and subjectivism of the Sophists provoked the emergence of many bold hypotheses in various fields of philosophical and natural science knowledge. However, the activity of the Sophists had its reverse: proclaiming that "man is the measure of all things: of things which are and of things which are not", the Sophists engaged "the mode of relativity" (6, P. 216) amounting with nihilism and axiological arbitrariness (7, P. 69).

Socrates opposed exactly this tendency. Supporting the Sophists in their desire to turn towards man, his subjectivity and the rational reasoning of his professed system of values, the great thinker tried to limit the voluntarism of the Sophists, determining intersubjective boundaries of personal arbitrariness. And the Spirit or, in other words, the rational basis of all being which is cognizable through the analytic activity of human consciousness serves as these boundaries. Socrates, disclaiming the authority of gods as well as subject-empirical reality, nevertheless opposed the Idea to the subjectivism of the Sophists. For the Sophists, man in his individuality and originality was the main object of examination. For Socrates, man remained the main object of examination as well but in another perspective: he considered man, in the first place, as an idea mostly characterized by reason comparable to the ontological rationality of the universe. For Socrates the question of the human ideal became crucial - the question which was ignored by the school of the Sophists and which, according to the Athenian philosopher, must be the goal of scientific knowledge.

If the beginning of the wisdom is the awareness of the fact that you know only that "you know nothing" (8, P.80), so along with the desire to cognize arises the question about the comprehension of nature and peculiarity of the cognizer himself and his universal, unconditional meaning (9, P. 6). From the "very beginning" on Socrates attempted to find out what in our knowledge is random and incidental and what is universal and essential. Through this methodological presupposition the philosopher approaches, on the one hand, the necessity to develop logical rules, in particular, the 
rules of defining the object (through generic and species traits), on the other hand, the substantiation of ontological status of spiritual values. What is, for example, piety? Is piety pious because people or gods decided so or, on the contrary, people and gods perceive piety to be so because it is so on its own (10, P. 7e-10e)? For Socrates, spiritual values don't depend on human relativity; they are self-sufficient and objective. Despite the fact that spirit is transcendent, it is, nevertheless, objective and therefore cognizable through reason. This conclusion about simultaneous objectivity (ontologicality) and transcendence of spirit proved to be crucial for all subsequent idealistic tradition in philosophy as well as for future rational interpretation of Christianity.

In this situation Socrates maintains rather compromise position on the interpretation of the spiritual, overcoming the extremes inherent to the preceding philosophical movements as well as to some subsequent ones. We mean, on the one hand, the schools of the Eleatics and the Sophists which considered the world of empirical givenness an illusion, a semblance, and only the reason of the individual was able to impart some constancy and sense to it. On the other hand, already for Socrates' disciple, Plato, the transcendental Idea became the meaning-formative axis of being. The Idea is tragically separated from the world of things; it determines this world and lives by its own autonomous laws. But for Socrates the transcendental and objective Spirit imparts essential unity to the laws of the Universe and human thinking, making both of them the correlators of physical-empirical being.

Underlining the ontologicality of the transcendental Spirit and its fundamental affinity with human reason and human intellectual capacity, Socrates greatly extended human epistemological boundaries, laying the theoreticalmethodological foundation not only for idealistic schools of philosophy, but also for "positive" theology. Here we perceive one of the key points determining the influence of the ancient thought on the development of the Christianity in its rational form. We believe that from this very rationalistic optimism emerge most of the rationalistic interpretations of Christianity which are characteristic both of Western European patristics and late medieval scholasticism. If we interpret Christianity as "the reflection of divine reason", hence "it can be understood as a religion of reason" (11, P. 69).

The absolute reason serves for Socrates as the source of science and ethics, knowledge and virtue. Morality for him is an immanent attribute of the true knowledge. He asserted not without reason that "all knowledge, when separated from justice and virtue, is seen to be cunning and not wisdom" (12, P. 247) and that "virtues are properties of reason because they all are knowledge" (13, C.13). So, Socrates proposed one more idea - the idea of ethical attribution of the transcendental Spirit - which proved to be demanded by medieval Christianity. Calling to the knowledge of the human self and higher spiritual laws, Socrates underlined at the same time that the knowledge on itself doesn't have its goal in itself; it only serves as a mean of perfection of moral principles. The transcendental basis of the world has an unconditional moral sense and the cognition of this moral sense is both the purpose of human life and the highest sense of human activity. The ethical thrust of Socrates' teaching marked the most important axiological presupposition of early Christianity for which the love to the neighbor and God's to people became the universal principle of human existence.

The boundless faith in ethical principles brought Socrates to the belief that "no evil can happen to a good man, either in life or after death. He and his are not neglected by the gods" (14, P.41). The absoluteness of the moral law and its unconditional value became the source of an even more important thesis of nonresistance which is characteristic both for Socrates' philosophy and for the Christian system. Anticipating the ethics of the New Testament almost literally(15), Socrates preached that "we ought not to retaliate or render evil for evil to anyone, whatever evil we may have suffered from him" (16, C.49).

\section{The Foundation Laid by Plato and Arisotle}

Plato and Aristotle adopted their attitude towards reason as the most important source of cognition of reality from Socrates. Following Socrates, Plato (428-348) consistently adheres to the idea that spiritual reality can't be conditioned by empirical facts. It can have its basis only in itself $(4$, P.146). For the first time in the history of philosophy Plato noted the fact that people perceive real things not directly but mediately through ideas. The world of empirical facts acquires sense and value only being involved in the system of ideal links and relations. So, whereas any element of empirical reality is imperfect, finite and limited by temporal and spatial boundaries, any idea, on the contrary, is perfect and eternal, it isn't limited by any confines. From here Plato drew the conclusion about the absoluteness of the world of ideas and the relativity of the world of things. Hence one more conclusion can be drawn: only intelligible forms or ideas can serve as the object of epistemology and not the corporeal-material being. So, according to Plato, matter can't exist autonomously; matter is real only to the extent in which it takes part in the immediate being of things (17, P. 132, 141, 151). Such a strict opposition between spiritual reality (as a real, absolute and perfect reality) and material, corporeal and empirical reality (as a forming and not self-sufficient reality) later played an important role in the development of Christian philosophy. Just in the manner of Plato Christianity tends to state that "truly there is only the intelligible world which is not created by 
human thinking. It is the assemblage of verities - first principles and mathematical verities injected in our spirit" (18, P.104).

According to his conception, Plato revised the notion of truth which no more could be identified just as some correlation between things and their representation. Practice also couldn't be qualified as the criterion of truth because it is usually conducted in the sphere of empirical, forming and untrue being. The absoluteness of spiritual reality defines the truth as the fact of identity of spirit with itself. So, the truth is disclosed to people as an idea. To contemplate the truth means to see the being in its ideal essence, in its "unconcealment" (Martin Heidegger, one of the most remarkable commentators and followers of Plato in his teaching about the truth, underlined that "cognizable itself as such must appear, disclose, in order for knowledge, and for the sentence that forms and expresses it, to correspond to the facts it is necessary, first of all, that the fact which is to be binding on the sentence show itself to be such"). Construing the truth in this way, Plato bridged the chasm between the nature of the perceiver and the perceived. According to Plato, ideas are a substantial basis that unites the true being with the mechanisms of subjective cognition of this being.

Practically, from all aforesaid follows that the sense of human existence is the maximum entry into the spiritual sphere. Distinct awareness of the illusiveness of the corporeal-empirical world, leveling of sensual passions and the practice of transcensus must contribute to it. But since the true being is transcendental and quite different from the appearing and forming being with which sensual experience is concerned, so the ways of contemplating of the true being can't be the same as those used to contemplate the world of empirical reality. To contemplate a transcendental idea means to see it in its immediate appearance and self-evidence. Plato overcame here the tendency to ontologize the formal logic which was typical for the school of Eleatics and offered an absolutely different epistemological system which used overrational ways of cognition of the world.

The appeal to the irrational-mystical became for Plato necessary in methodological terms to provide the immediate vision of the world of ideas. This was the reason why he didn't content himself only with formal-logical means of human mind and insisted on the necessity to get into the ecstatic state which provided the proper emotional-psychological state (5, P. 210 a - 212 a).So, according to Plato, strictly rational, logical methods form only the lower grade of cognitive process. Logic only discloses the paradoxicality and inconsistency of the world of things and helps people to become aware of subjectivity of opinions and conditionality of sensual reality $(19, \mathrm{C} .230)$. Paradoxes and contradictions to which a strictly logical mind comes only testify to the paradoxicality and inconsistency of the untrue being. The world of transcendental ideas is above inconsistencies and paradoxes. The absolute truth is consistent and identical to itself $(20$, C.52).

However, the philosophy of Plato left many questions unanswered. First of all it concerns the dualistic interpretation of the being and the ascertainment of two worlds which are practically independent from each other - the ideal world and the corporeal world. The mechanism of their interdependence and interaction also proved to be not quite distinct. If we characterize the world of ideas as absolutely self-sufficient, independent and perfect, the mechanism and the meaning of extrapolation of ideas to the objects of material reality. If the world of ideas is absolutely autonomous, how can we explain the belonging of single objects to this world? For, as we have written earlier, the material world has "no firm link with the ideal world. The interlacing of the transcendental idea with mankind and of the absolute spirit with matter is not an actual fact but only a potential goal" (21).

All these questions were central in the philosophy of Aristotle (384-322). Aristotle took as principal objective the attempt to bring things and ideas, the universal and the single together, to find their common ground, to elaborate the system of determinations between them (9, P. 1079 a - 1079 b).

To achieve these goals Aristotle offered a hypothesis according to which the ideas of things lie inside the things themselves, though in a not quite actualized form. The matter is constantly "forming" or, in other words, acquiring the form. The striving for its forming is an immanent property of a material-sensual object. The form is actually the idea of a thing through which it obtains the sense and essence. Hence the idea or the form contained in the object induces the development of the corporeal-sensual world towards its perfect state, conditions the evolution from the individual to the universal, from the material-nonperfect to the ideal-perfect. But, connecting in such way the matter and the idea, the corporeal-sensual and the spiritual-transcendental, the individual and the universal, Aristotle approaches a new problem. The ontological status of ideas proved to be very unclear for Aristotle because, on the one hand, they dwell in things and they are actually their forms, on the other hand, the entities of things or their forms are by definition something immaterial. Hence also emerged a purely epistemological problem. On the one hand, if ideas lie in things, we must direct our knowledge to the things themselves. On the other hand, Aristotle himself admitted that sensual perception is a perception of singularities, accidents and therefore it can't serve as a basis of the cognitive process aimed at the discovery of the necessary, persistent and permanent (13, P. 22-24).

In our opinion, all these hardships and contradictions emerged in the system of Aristotle are to a great extent 
caused by his orientation on strictly logical methods which prescribe systematic and consistent cognition. Furthermore, unlike Plato for whom the world of ideas was transcendental and thus the contact with the transcendental world allowed the practice of contemplation based on alogism, nondiscursivity, nonverbality, for Aristotle who maintained a position of strictly logical thinking such logic was inadmissible. One of the main principles formulated by Aristotle: "it is impossible that one and the same at one and the same time should be and not be inherent in one and the same thing in one and the same relation" (9, P. 15-20) proved to be fully applicable to ideas too. That was why Aristotle, approaching inconsistencies, was quite indisposed to think that they are inherent in things themselves. Hence he interprets the truth absolutely differently as compared to Plato. For Aristotle, the truth isn't an ontological property of the spiritual reality; it is the result of the relation of human mind to the objective reality of the sensual world $(9$, P. 25). Overcoming the idealism and the transcendentalism of Plato, Aristotle, basing on the rational-logical methods, comes to a hypothesis that ideas don't have their own independent reality and autonomy. Ideas are contained in things themselves and only in them (9, P. 3). For to assert that the idea-essence of a thing dwells inside it and at the same time outside of it means to contradict the fundamentals of logical thinking themselves.

We might consider all these reasonings of Aristotle as materialistic, but there is one important point. Wherever Aristotle places the ideal essence of the corporeal-empirical being, the question of the objectivity of this essence remains open. If we suppose that ideas don't have their own existence and they are only attributes of single things, we thereby doubt the possibility of knowledge itself. For the world of things, by Aristotle's own admission, is multiple and consists of some singularities. And if only it has an unconditional ontological status, so we can't even speak about any universality and substantiality of being. And even if we admit in this case that there is a possibility to establish some universal connection between single objects, this connection would be inevitably relative, subjective and devoid of intersubjectivity. Hence, the development of scientific knowledge and objective scientific criteria itself is questioned.

Feeling this threat and trying to save methodological presuppositions of scientific knowledge, Aristotle had to assume the existence of some objective regularity which stands over things and ideas. Only the presence of such regularity, of the "idea of all ideas" allows us to consider being as a system which is subordinated not to the subjective arbitrariness of human mind but to some objective goal. The necessity to assume such "idea of all ideas" is crucial for the philosophy of Aristotle. This assumption is absolutely necessary to construct the ontological theory because without objective regularity being crumbles into infinitely many singularities. Without such assumption it's also impossible to decide the most important epistemological questions because otherwise the reason becomes devoid of any criteria of knowledge. The "idea of all ideas" also has a profound aesthetic meaning because it's the ideal the matter strives to; it also serves as an absolutely perfect object, a "pure form" (9, P. 6-7).

Actually, this issue concerns the substantiation of God's existence and God as the sense-giving force of all being. Hence it's natural that medieval patristics repeatedly appealed to logical arguments of Aristotle and, as A.F. Losev rightly noted, if it hadn't been for Aristotle's vast argumentation of the necessity to admit the existence of the "idea of all ideas" as a universal regularity, "Aristotelianism couldn't have taken its lead in medieval Western theology" (22, P. 609).

So, criticizing Plato for the world of the transcendental ideas that he created, Aristotle himself comes to the substantiation of the spiritual Absolute but of some other kind. Denying the transcendental idealism, he actually comes to a theological conception, to the substantiation of the idea of God as a necessary condition of endowing the being with objective meaning and objective appropriateness. According to V.N. Kuznetsov, for ancient idealism it's typical to "insist on the existence of a supernatural regularity which is divine in its essence; that was why the task of revelation of world theology was set before reason" (23, P. 11). In justice to Aristotle it should be admitted that he managed to avoid dualistic problems typical for Plato's philosophical system and to create a universal (though bulky) model of the world. For Aristotle, the corporeal-empirical world is absolutely real; so are ideas which exist in single things, so is the matter which is constantly developing and striving after its final "forming". So, all this world acquires sense, goal and objectivity, permeated with the idea of Absolute. If we interpret this thought in theological categories, we can say that the sensual world is transformed and spiritualized due to its participation in God and Sophia. However, it should be remembered that "the cosmological point of view is rather rare in Aristotle's writings. Aristotle does not very often give an overview of the world and explain things "from above". His interest is far more often taken up with a local perspective, focusing on specific, small-scale features of natural entities and processes" (24, P. 33).

One more victory achieved by Aristotle consisted in rehabilitation of strictly systematic thinking and rational-logical cognition. Transposing ideas into things themselves, into the objective-empirical world, Aristotle gives to understand that knowledge is based not on the "beholding" of otherworldly platonic ideas but on the systematic study of the tangible world. Whereas for Plato truth is transcendental and so it can be properly caught only through an irrational-mystical act, an intuition, a "virgin" beholding, for Aristotle truth is the relation of human subjectivity to the quite this-worldly objective reality. And if so, it can be achieved through logical means of knowledge only (9, P.25). 
Plato and Aristotle defined absolutely different approaches to philosophy expressing most distinctly two tendencies which were outlined in antiquity and continued in the Middle Ages. It isn't the opposition of materialism and idealism. Both Plato and Aristotle were undoubtedly idealists: the one - because he transposed the true reality into the sphere of the spiritual, underlining the secondariness and derivativeness of the material and sensual reality; the other - because the "idea of all ideas" or God is the highest sense and goal of all being for him. However, the gap between these two philosophers is enormous. As a matter of fact, Plato and Aristotle take totally opposite stands on the question of the essence of philosophy, its subject and methods; they appeal to mutually incompatible interpretations of the very bases of being. For Plato, true being is spiritual, transcendent; it doesn't fit in any rational-logical boundaries. For Aristotle, true being is corporeal and sensual; it is quite cognizable through rational-logical thinking. For Plato, the corporeal-sensual is an illusory "shade" of spirit; for Aristotle the very absolute spirit is a theoretical assumption, and this compulsory assumption, as a methodological admission, is necessary to substantiate the reality of the corporeal-sensual, "bodily" world. Aristotle most clearly formulated the idea of rational-logical totality which was very popular in ancient metaphysics and with which naturalistic philosophers, the Eleatics and the Sophists were mostly concordant. Whereas Plato "discovered" the transcensus and outlined the ways to the overrational and rather to the irrational-mystical comprehension of philosophical problems. In this sense, he constituted the opposition to the rational-logical tradition of ancient Greece as well as Orphics and Pythagoreans. Plato argued that the truth is the spiritual reality itself which is initially exposed to people: it is beyond contradictions and it embodies true being. He concludes from this that forms of being and forms of logical thinking are different. For Aristotle, on the contrary, the truth is the correspondence between forms of thinking and forms of being; it's not the reality, but the reflection of the reality in structures of human consciousness. It is notable that this very treatment of the truth gained a foothold in West European philosophy and science.

\section{Platonism and Aristotelianism in Christianity}

These two tendencies, aimed at the development of the rational and irrational models of the world, were elaborated further in the Christian tradition, continually "arising" in the form of discussions of the relation between faith and knowledge, of different ways of knowledge of God. Thus, as it seems to us, the followers of Aristotelian tradition which affirmed that "the reason is twice as necessary to unfold the faith fully" (3, P.115) evidently prevailed in West European Christianity. As a result, a quite powerful tendency developed - the tendency to interpret Christian doctrine rationally and logically, the conception of "finding way to Jerusalem through Athens" which tried to present the Christian conception as a theoretical discipline properly describable in terms of science (25, P.70).

West European Christianity, turning to the heritage of ancient philosophers and particularly to the Aristotelianism for a metaphysical substantiation of religious dogmas, formulated a number of crucial problems. First of all it's the problem of the dialectical unity of faith and reason, the problem of transcendental object of knowledge and the application of mechanisms of rational epistemology to it. For a European mind which is used to appeal to common sense and intellectual forms of information processing, to realize that logical conclusiveness is the criterion of truth, the turn to the transcendental-mystical has been always problematic. The desire to cognize everything, to enclose everything in the framework of a single epistemological system didn't leave out the idea of God. Proceeding on this path, West European Christianity was guided by Aristotelian principles and often set an artificial limit to the infinity and preferred to consider the Christian conception by means of philosophical notions even if they were antinomic, as if being afraid to rise over the inconsistency of being.

It was caused mostly by the anxiety to lose distinct boundaries in the substantiation of the world order. For religion, according to many West European theologians, can lose the expedient justification of the good and the evil and so lose its ethical value if it admits the irrationality and mysticity of the basis of being and its immunity to the laws of rational thinking. However, such adherence to the rational totally overlooks some kinds of cognition, in particular, aesthetic cognition which is, as we have written earlier, "extrarational in its mechanisms, it is guided not by hypothetico-deductive structures of consciousness, but by emotional-psychological ones... It is no secret that spiritual life defies total and exhaustive analysis for that very reason that it contains irrational laws in a greater degree" (26). In this context the words of Justin the Philosopher (132-167) are very significant: in matters of faith he called to rely on epistemological criteria elaborated by ancient philosophy. This call remains relevant for the Western Christianity to this day (27, P.240). Of course, this rationalistic line in Christianity had its opponents which distinguished the spheres of reason and faith and stood up for the non-verbalizability and non-discursivity of religious experience. For example, Tertullian (160-220), assuming that the basis of all being, God "surpasses any thinking", actually associates himself with Plato's transcendentalism and takes the path of emotional-sensual, intuitive gnosticism. However, the position of Tertullian and 
his associates wasn't typical for West European Christianity. This was indirectly evidenced by the ideological conflict which eventually took place between him and the official Roman Church. Apparently, it is necessary to admit that followers of the rational-logical approach to Christianity "constantly prevailed, there were always more of them and they were setting the pace" $(28, \mathrm{P} .43)$ in Western Europe.

The conception of "rational faith" which tried to unite rational philosophy and Christian dogmatics has been developing since as early as by Clement of Alexandria in the 2nd century (?-215). Titus Flavius relied on rational tradition of Greek philosophy not only to underpin the religious sense with the intellectualistic basis, but also to make the new religion more "attractive". It is well known that Clement's sermons were sprinkled with quotations from the ancient philosophy; his famous "Stromata" (literally: "Patchwork") can be easily considered as Neoaristotelianism addressed to the "thinking", philosophizing elite of that time. The thought that reason is the true way to God was reflected by Clement of Alexandria in his substantiation of the place and the role of rationalistic philosophy in the process of knowledge of God. It is to be recalled that the well-known thesis "philosophy is the handmaiden of theology" belongs to him. In "Stromata" he writes: "Philosophy, therefore, is a preparation paving the way to Christ" (29, P. 5). Developing Aristotle's conception, Clement substantiates the universalism of the rational basis characteristic both for God-logos and human consciousnesslogos. Actually, for him Christ is Logos which was already found by ancient thinkers and which constitutes the united basis of the universe. He considers human mind as a "rational" microcosm identical to the "rational" macrocosm in its principal properties. So, Clement tried to accomplish one of the most daring attempts in the history of Christianity - the attempt to create a strictly scientific, systematic theology. Eventually, many ethical and aesthetic values were replaced by purely epistemological values in Clement of Alexandria. For the ideal man, according to his teaching, is a man moving along the path to Logos; the goal and the sense of human life consists not so much in becoming beneficent as in becoming cognizant - becoming a "perfect gnostic" (29, P. 28). And this thesis became one of the pivotal for almost all Western patristics.

St. Augustine's (354-430) theological conception wasn't as unambiguous as Clement's. The point is that a compromise between faith and knowledge, intuition and reason is characteristic for St. Augustine. This compromise was conditioned primarily by his orientation on Platonism. His connection with Plato is traced most easily in the belief that God's existence can't be deduced from the existence of the objective-sensual world but only from the human subjectivity. But Augustine's connection with Plato's heritage doesn't go far beyond that because he interprets the human subjectivity itself with a certain degree of intellectualism. Despite the profound psychologism of his works based on the experience of religious feeling, Augustine doesn't cross the line that separates intellectual reflections from transcensus. Still the religious-philosophical system of Augustine doesn't give adequate grounds to account it to "mystical" and "irrational". The rational basis remains the most important source of the knowledge of God for him, and this source has to bring man to God, to the true "comprehension and knowledge" of Him (30, P. XXIV). With all the ambiguity of St. Augustine's account we can state that he remains in the position of identification of the divine reason with human reason, of Logos, "God-truth" with the objective truth cognizable by means of rational activity. In this pivotal point he undoubtedly withdraws from the Plato's "methodology" of cognition of spiritual reality approaching the idea of rational totality of Aristotle. The identification of the forms of self-knowledge and self-realization of Logos with the forms of logical knowledge, as it was fairly noted by the famous historian of philosophy G.G. Mayorov, "has a double result: the divinization, theologization of theoretical rational knowledge and the rationalization of the Christian God" (31, P. 277).

So it was quite natural that Western European patristics, proceeding on the path of uniting Hellenistic philosophy in its rational form with Christian dogmatics, eventually came to scholastic doctrines in which the role of faith actually became indistinct and fuzzy due to its total submission to reason. Thomas Aquinas (1225-1274) - the central figure of Western European scholastics - frankly declares of the immanent rationality of divine actions and affirms the rational matter of the activity of the Absolute (32, P. 346). Thomas Aquinas writes that "God by His grace unites Himself to the created intellect, as an object made intelligible to it" (33, 1 q, 12, 4 c). Aquinas didn't deny the importance of faith in the process of knowledge of God, but practically he preferred to identify it with rational activity. As a result, "common sense" which is alien to the idea of transcendence became for him the basis of the theological construction. Even proofs of the existence of God Aquinas deduced from the facts of objective-empirical being.

\section{Conclusion}

So, in the process of development of the Western Europe model of the world scholastics came to ambiguous results: on the one hand, it required a very rich experience of Hellenistic traditions in the sphere of usage of scientific, rational-logical apparatus and thereby contributed to some "softening" of strict theocentric traditions of medieval world view. Later on, in modern era, this played an important role in the revival of scientific methodology, which stimulated the growth of the 
natural science sphere of knowledge. However, on the other hand, the scholastic interpretation of Christianity paved the way for the self-destruction of transcendental, sacred basis of religious experience. Deducing the existence of God from things, spiritual reality from the objective-empirical reality, appealing to "common sense" and this-worldly facts, scholasticism practically started the process of "blurring" of religious consciousness. Overcoming the dual structure of the universe and creating practically single objective-empirical reality permeated by the rational appropriateness of divine Logos, Thomas Aquinas brings together the religious world model and the mythological one.

Thomas Aquinas insisted that "almost all philosophical quests are directed towards the knowledge of God" (34, C.4). However, his synthesis of philosophy and theology was realized on the basis of rationalistic methodology which proved to be a universal, common foundation both for metaphysics and Christianity. Aquinas was subjected to sharp bidirectional criticism for it: on the one hand, the representatives of scientical philosophy which maintained positivistic approach to metaphysics disagreed with the theological "compromise" of logical-cognitive epistemology; on the other hand, many followers of the "mystical" line in Christianity, being committed to transcendentalism and fundamental irrationality of religious experience, on the contrary, considered the inclusion of rational-logical mechanisms in the process of knowledge of God inadmissible because the logization of faith eventually leads to its degradation and selfdestruction. In our opinion, both are mostly right. Actually, the criticism of scholastic interpretation of Christianity is based, on the one hand, on the inconsistency of rationalization (strictly scientific, logical, discursive, analytical substantiation) of the mysticism (the religious, irrational, transcendental), and, on the other hand, on the tampering (intuitive-sensual, emotional-psychological, ecstatic, overrational substantiation) of the rational (based on logic, discursivity, verbality, systematicity, verification).

V.I. Garadzha fairly noted that the system of Thomas Aquinas "didn't (and couldn't) yield the organic synthesis of reason and authority he strived for. It's an example of theological tampering of the Aristotelian philosophy, an example of arbitrariness and violation of logic and reason" (35, P. 87). We would like to add that it also can be fairly considered a rationalistic tampering of Christianity and an example of rational-logical "violation" of faith and religious experience.

Nevertheless, the ideas of Thomas Aquinas became predominant for Western European Christianity. According to A. Dondeyne, his conception became "classic in the Catholic Church and remains so till now" (3, C.118).

\section{References}

Xenophon of Athens (1935). Memorabilia. Socratic works, I, 4; 8. Moscow, Leningrad.

Gabinsky, G.A. (1976). Theology and logic. Philosophical sciences, 6.

Dondeyne, A. (1974). Contemporary European Thought and Christian Faith. Brussels.

Plato (1970). Theaetetus. Selected works in three volumes (Vol.2). Moscow.

Plato (1970). Symposium. Selected works in three volumes (Vol.2). Moscow.

Sextus Empiricus (1976). Outlines of Pyrrhonism. Selected works in two volumes (Vol.2). Moscow.

Zeller, E. (1912). The essay on history of Greek philosophy. Moscow.

Plato (1968). Meno. Selected works in three volumes (Vol.1). Moscow.

Aristotle (1969). Metaphysics. Selected works in four volumes (Vol.1). Moscow.

Plato (1923). Euthyphro. The complete works in fifteen volumes (Vol.1). St. Petersburg.

Ivanov, N. (1966). Saint Justin Martyr. The journal of Moscow Patriarchate, 7.

Plato (1970). Menexenus. Selected works in three volumes (Vol.2). Moscow.

Aristotle (1908). Nicomachean ethics. Ethics of Aristotle (Vol.2). St. Petersburg.

Plato (1968). Apology. Selected works in three volumes (Vol.1). Moscow. Mt. 5:39

Plato (1968). Crito. Selected works in three volumes (Vol.1). Moscow.

Plato (1970). Parmenides. Selected works in three volumes (Vol.2). Moscow.

Masset, P. (1973). Comment croire? La foi et la philosophie moderne. Paris.

Plato (1970). Sophist. Selected works in three volumes (Vol.2). Moscow.

Plato (1970). Republic. Selected works in three volumes (Vol.3). Moscow.

Kortunov, V.V. (2013). Sophian world vision. Middle-East Journal of Scientific Research, 14 (7). Retrieved from http://philosoph.ru/ teacher/kortunov-vadim-vadimovich/\#!sophian-world-vision-middle-east-journal-of-scientific-research-14-7-2013

Losev, A.F. (1975). The history of classical aesthetics: Aristotle and late classics. Moscow.

Kuznetsov, V.N. (1983). Constitution of philosophical rationality. Diversifications and conflict of rationalities in the ancient philosophy. Reason and culture. Moscow.

Tuominen, M. (2014). New Perspectives on Aristotelianism and Its Critics. Brill Academic Publishers.

Babosov, E.M. (1971). Scientific-technical revolution and modernization of Catholicism. Minsk.

Kortunov V.V. (2014). Russian philosophy between western metaphysics and eastern mysticism. European Journal of Science and Theology, 9 (5). Retrieved from http://philosoph.ru/wp-content/uploads/2014/11/5_Kortunov_5_Kortunov2014_11_12_21_31_ 14.pdf 
Maritain, J. (1966). Le Paysan de la Garrone. Paris.

Orgish, V.P. (1986). Ancient philosophy and the origin of Christianity. Minsk.

Clement of Alexandria (1892). Stromata. Yaroslavl.

Augustine of Hippo (1912). Of true religion. Kiew.

Mayorov, G.G. (1979). Formation of Medieval Philosophy: Latin patristics. Moscow.

Sokolov, V.V. (1979). Medieval philosophy. Moscow.

Thomas Aquinas (1969). Summa theologiae. Anthology of world philosophy in four volumes (Vol.1). Moscow.

Thomas Aquinas (1969). Contra gentiles. Anthology of world philosophy in four volumes (Vol.1). Moscow.

Garadzha, V.I. (1969). Neo-Thomism - reason - science: the critique of the Catholic conception of scientific knowledge. Moscow. 